\title{
Histopathology and microcystin distribution in Lymnaea stagnalis (Gastropoda) following toxic cyanobacterial or dissolved microcystin-LR exposure
}

\author{
Emilie Lance ${ }^{\mathrm{d}, *}$, Celine Josso $^{\mathrm{b}}$, Daniel Dietrich ${ }^{\mathrm{c}}$, Bernhard Ernst $^{\mathrm{c}}$, Chrystelle Paty $^{\mathrm{b}}$, \\ Fabrice Senger ${ }^{\mathrm{d}}$, Myriam Bormans ${ }^{\mathrm{a}}$, Claudia Gérard ${ }^{\mathrm{a}}$ \\ a UMR CNRS 6553 ECOBIO, Université de Rennes 1, 263 Avenue du Général Leclerc, CS 74205, 35042 Rennes, France \\ ${ }^{\text {b } U M R ~ I N R A ~ B i o 3 P, ~ U n i v e r s i t e ́ ~ d e ~ R e n n e s ~ 1, ~} 263$ Avenue du Général Leclerc, CS 74205, 35042 Rennes Cedex, France \\ ' Human \& Environmental Toxicology Group, University of Konstanz, D-78457 Konstanz, Germany \\ ¿ UMR CNRS 6026, Université de Rennes 1, 263 Avenue du Général Leclerc, CS 74205, 35042 Rennes Cedex, France
}

Keywords:

Microcystins

Gastropods

Cyanobacteria

Histopathology

Digestive gland

Genital gland

\begin{abstract}
A B S T R A C T
The accumulation of hepatotoxic microcystins (MCs) in gastropods has been demonstrated to be higher following grazing of toxic cyanobacteria than from MCs dissolved in ambient water. Previous studies, however, did not adequately consider MCs covalently bound to protein phosphatases, which may represent a considerably part of the MC body burden. Thus, using an immunohistochemical method, we examined and compared the histopathology and organ distribution of covalently bound MCs in Lymnaea stagnalis following a 5-week exposure to (i) dmMC-LR, dmMC-RR, and MC-YR-producing Planktothrix agardhii ( $5 \mu \mathrm{g} \mathrm{MC-LReq} \mathrm{L}^{-1}$ ) and (ii) dissolved MC-LR (33 and $100 \mu \mathrm{gL}^{-1}$ ). A subsequent 3-week depuration investigated potential $\mathrm{MC}$ elimination and tissue regeneration. Following both exposures, bound MCs were primarily observed in the digestive gland and tract of $L$. stagnalis. Snails exposed to toxic cyanobacteria showed severe and widespread necrotic changes in the digestive gland co-occurring with a pronounced cytoplasmic presence of MCs in digestive cells and in the lumen of digestive lobules. Snails exposed to dissolved MC-LR showed moderate and negligible pathological changes of the digestive gland co-occurring with a restrained presence of MCs in the apical membrane of digestive cells and in the lumen of digestive lobules. These results confirm lower uptake of dissolved MC-LR and correspondingly lower cytotoxicity in the digestive gland of $L$. stagnalis. In contrast, after ingestion of MC-containing cyanobacterial filaments, the most likely longer residual time within the digestive gland and/or the MC variant involved (e.g., MC-YR) allowed for increased MC uptake, consequently a higher MC burden in situ and thus a more pronounced ensuing pathology. While no pathological changes were observed in kidney, foot and the genital gland, MCs were detected in spermatozoids and oocytes of all exposed snails, most likely involving a hemolymph transport from the digestive system to the genital gland. The latter results indicate the potential for adverse impact of MCs on gastropod health and reproduction as well as the possible transfer of MCs to higher trophic levels of the food web.
\end{abstract}

\section{Introduction}

The cyanobacterial microcystins (MCs) have been associated with acute and subacute adverse effects in various aquatic and terrestrial organisms (for reviews: Wiegand and Pflugmacher, 2005 Malbrouck and Kestemont, 2006). MCs can enter the aquatic food web via accumulation primarily in the liver and gastro-intestina tract of vertebrates and in the digestive gland of invertebrates (for reviews: Zurawell et al., 2005; Ibelings and Chorus, 2007; Martins

\footnotetext{
* Corresponding author. Present address: IRSN/DEI/SECRE/LME, Centre de Cadarache, Bat 159, BP3, F-13115 Saint-Paul-Lez-Durance Cedex, France. Tel.: +330223235037 .

E-mail address: emilie.lance@live, $\mathrm{f}_{\Gamma}(\mathrm{E}$. Lance).
}

and Vasconcelos, 2009). Once actively taken up, presumably via members of the organic anion transporting peptide (oatp) family (Fischer et al., 2005; Feurstein et al., 2009), into oatp-expressing cells, MCs specifically interact with serine/threonine protein phosphatases (PPs, e.g., PP1, 2A, 4, and 5) in a two-step mechanism involving a rapid and reversible binding to the PP catalytic subunit via a hydrophobic bond (i.e., accumulation of free MCs) followed by a slower binding involving the covalent interaction of the dehydroalanine moiety of MCs with cysteins of the PP catalytic subunit after several hours (i.e., accumulation of bound MCs) (Hastie et al., 2005; Maynes et al., 2006). Both covalent and non-covalent binding of MCs and subsequent inhibition of phosphatases results in hyperphosphorylation of numerous phosphate-regulated enzymes and subsequent deregulation of various fundamental cellular processes, such as disruption of the cytoskeleton (Eriksson et al., 1989; 
Yoshizawa et al., 1990; Batista et al., 2003). The latter further progresses to disintegration of organ architecture, thus pathological changes of the gastro-intestinal tract, liver and kidney of exposed organisms (vertebrates and invertebrates) (for reviews: Dietrich and Hoeger, 2005; Wiegand and Pflugmacher, 2005; Zurawell et al., 2005).

Freshwater gastropods inhabit the littoral area (Dillon, 2000) where scums are frequently formed during or subsequent to cyanobacterial blooms. Gastropods can therefore be exposed rapidly to toxins following ingestion of toxic cyanobacteria or exposure to dissolved or particle-adsorbed (extracellular) toxins released into the ambient water after cyanobacterial cell lysis. Field observations suggest that gastropods accumulate free MCs mainly by grazing toxic cyanobacteria, and to a lesser extent via uptake of dissolved toxins in the ambient water (Kotak et al., 1996; Zurawell et al., 1999; Chen et al., 2005; Xie et al., 2007; Zhang et al., 2007; Gérard et al., 2008). Moreover, the ability of MCs to accumulate in tissues and to impair digestive gland homeostasis has been demonstrated in the pulmonate Lymnaea stagnalis following consumption of toxic cyanobacteria and exposure to dissolved MC-LR in experimental investigations (Gérard et al., 2005; Lance et al., 2006, 2007; Zurawell et al, 2006, 2007). Indeed, after consumption of toxic cyanobacteria, 61.0 and $1.3 \%$ of total ingested MCs were found accumulated in L. stagnalis and the prosobranch Potamopyrgus antipodarum, respectively, which also resulted in increased morbidity of both species (Lance et al., 2006, 2007, 2008). Adverse effects on lifehistory parameters were also observed following immersion of $L$. stagnalis and $P$. antipodarum in $33 \mu \mathrm{g} \mathrm{MC-LRL}^{-1}$. However, a decisively lower MC accumulation was recorded when compared to animals orally exposed to whole toxic cyanobacteria (Gérard et al., 2005; Gérard and Poullain, 2005). Previous investigations therefore suggest that $\mathrm{MC}$ accumulation and subsequent pathological effects largely depend on the route and form (dissolved vs. intracellular toxin) of exposure. This assumption is corroborated by the recent findings of Lance et al. (2010), who demonstrated the accumulation of covalently bound microcystins in tissues of $L$. stagnalis exposed to toxic cyanobacteria, whereas bound MCs were not detected in $L$. stagnalis exposed to dissolved MC-LR

However, most previous studies on the influence of MCs on molluscs did not discriminate between reversibly and covalently bound MCs, although covalently bound MCs can represent a quantitatively large portion of a given MC body burden (Lance et al., 2010). Indeed, covalently bound MCs are potentially bioavailable and thus the more critical for mollusc-consuming species at higher trophic levels (Dietrich and Hoeger, 2005; Ernst et al., 2005). Therefore the aim of this study was to examine the tissue distribution of covalently bound MCs and histopathological changes in various organs (digestive gland, genital gland, kidney, foot) of L. stagnalis, exposed to MC-producing Planktothrix agardhii ( $5 \mu \mathrm{g} \mathrm{MC-LReq} \mathrm{L} \mathrm{L}^{-1}$ ) and to dissolved MC-LR ( 33 and $100 \mu \mathrm{gL}^{-1}$ ). The latter should allow determining whether:

- cyanobacterial and dissolved MC exposure induce similar histopathological changes:

- the histopathological changes observed correlate with the intensity (relative quantity) and localization of covalently bound MCs;

- covalently bound MCs are eliminated and tissue regeneration occurs following a defined depuration period.

\section{Materials and methods}

\subsection{Biological material}

L. stagnalis adults were obtained from a laboratory population in the Experimental Unit of the Institut National de Recherche en
Agronomie (INRA, Rennes). Prior to experiment, adults $(25 \pm 3 \mathrm{~mm}$ shell length) were isolated in glass containers of $35 \mathrm{~mL}$ of dechlorinated and activated charcoal-filtered tap water ( 1 snail/container) acclimated to the experimental conditions $(12 / 12 \mathrm{~L} / \mathrm{D}, 20 \pm 1 \mathrm{C})$ and fed with biological (pesticide free) lettuce for 7 days. The filamentous cyanobacterium $P$. agardhii (strain PMC 75-02) was cultured as described in Lance et al. (2006) and produced three MC variants, dmMC-LR, dmMC-RR and MC-YR in various proportions, as determined by liquid chromatography electrospray ionisation tandem mass spectrometry (Lance et al., 2010; Neffling et al., 2010). The $P$. agardhii suspension contained a total concentration of $5 \mu g$ MC-LR equivalents (MC-LReq) per litre measured by high-pressure liquid chromatography with UV diode array detection (HPLC-DAD) using the method described in Lance et al. (2006). For dissolved MC-LR exposure, purified MC-LR (Alexis Corporation, USA) was solubilized with $\mathrm{MeOH}\left(1 \mathrm{mLL}^{-1}\right)$ in dechlorinated water for final dissolved MC-LR concentrations of 33 and $100 \mu \mathrm{g} \mathrm{L}^{-1}$.

\subsection{Experimental setup}

Following acclimatization, snails were divided into six exposure groups according to diet and medium: (1) dechlorinated water with lettuce ad libitum (CONTR), (2) dechlorinated water without feeding (STARV), (3) dechlorinated water containing $33 \mu \mathrm{g} \mathrm{MC-LRL}^{-1}$ with lettuce ad libitum (033LT), (4) dechlorinated water containing $100 \mu \mathrm{g} \mathrm{MC-LRL}^{-1}$ with lettuce ad libitum (100LT), (5) cyanobacterial suspension without additional feeding (CYANO), and (6) cyanobacterial suspension with lettuce ad libitum (CYALT). Groups consisted of 20 individuals kept separately. Medium was renewed twice a week. After the exposure period of 5 weeks, snails were placed into dechlorinated tap water and fed ad libitum with lettuce during 3 weeks (depuration period).

\subsection{Histopathology}

After exposure and depuration periods, four snails were removed from each exposure for histological investigations. Snail bodies were removed from the shell, and stomachs were taken off due to the presence of sand that could impair tissue during the sliding process. Possible shell residues on snail bodies were dissolved in ethylene diamine tetraacetic acid (EDTA) and prepared bodies were fixed in Bouin's fluid for $48 \mathrm{~h}$. Tissues were then processed as described in Lance et al. (2007), cut into serial $6-\mu \mathrm{m}$-thick longitudinal sections and stained with Hematoxylin \& Eosin (H\&E) (Martoja and Martoja-Pierson, 1967). Kidney, foot, digestive and genital glands were photographed in each section via an optic microscope using 40-200-fold magnification. Additional quantitative and semi-quantitative parameters were created (see MADLE, MDPC and PLIE below) for the pathological evaluation of the digestive gland, the only organ presenting significant pathological changes. Employing these parameters, 25 sections from each of the four snails per exposure were evaluated in order to qualitatively and quantitatively assess MC-induced pathology.

\subsubsection{Mean area of the digestive lobule epithelium (MADLE)}

Variations in the thickness of the digestive lobule epithelium were assessed via comparison of the areas of the digestive lobule epithelium, determined using microscopic images (magnification: 100) and the AnalySIS software (Soft Imaging System GmbH, Germany). The mean area of the digestive lobule epithelium (MADLE) per exposure was determined via averaging the mean area of the lobule epithelium from each of the four snails. For each snail, the mean area of the lobule epithelium was determined from $25 \mathrm{sec}$ tions. 

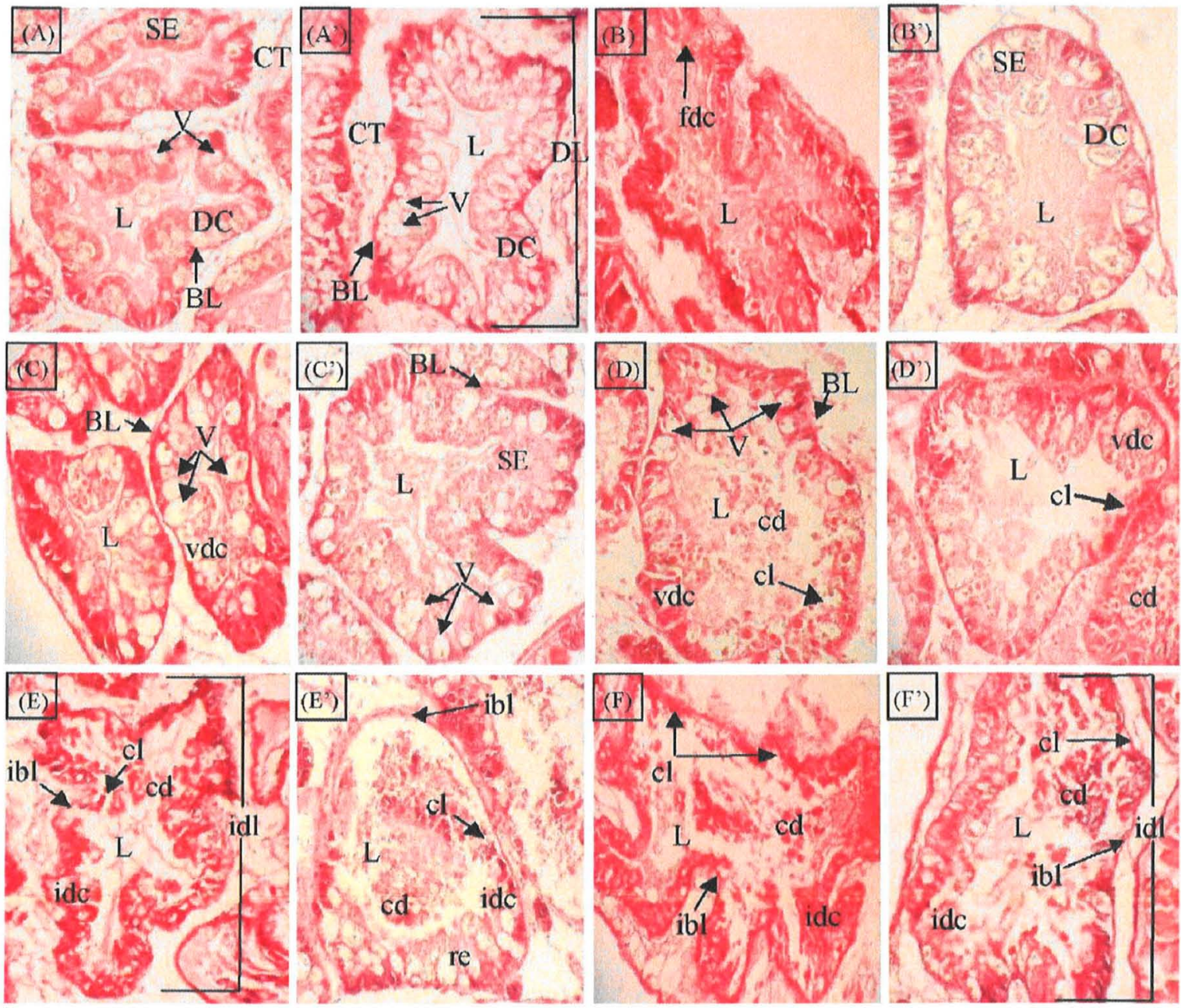

Fig. 1. Histopathological changes in the digestive gland tissue of Lymnaea stagnalis held in various treatment groups $(A=C O N T R ; B=S T A R V ; C=033 L T, D=100 L T ; E=C Y A L T ;$ $\mathrm{F}=\mathrm{CYANO}$ ) after 5 weeks of treatment $\left(\mathrm{A}, \mathrm{B}, \mathrm{C}, \mathrm{D}, \mathrm{E}\right.$ and $\mathrm{F}$ ) and 3 weeks of depuration $\left(\mathrm{A}^{\prime}, \mathrm{B}^{\prime}, \mathrm{C}^{\prime}, \mathrm{D}^{\prime}, \mathrm{E}^{\prime}\right.$ and $\left.\mathrm{F}^{\prime}\right)$. Sections were stained with $\mathrm{H} \& \mathrm{E}$ and observed by light microscopy at 62.5-fold magnification. See Table 1 for abbreviations of treatment groups. Normal structure is given in capital letters: $\mathrm{BL}=$ basal lamina, $\mathrm{CT}=\mathrm{connective}$ tissues, $\mathrm{DC}=\mathrm{digestive}$ cells, $\mathrm{DL}=$ digestive lobule, $\mathrm{L}=$ lumen, $\mathrm{SE}=$ structured epithelium and $\mathrm{V}=$ vacuoles; damaged structures are labelled with small letters: $\mathrm{cd}=\mathrm{cytoplasmic}$ debris, $\mathrm{cl}=\mathrm{cell}$ lysis, $\mathrm{fdc}=$ flattened digestive cells, ibl = impaired basal lamina, idc = impaired digestive cells, idl = impaired digestive lobules, re $=$ regenerating epithelium and vdc $=$ vacuolated digestive cells.

\subsubsection{Mean degree of pathological changes (MDPC)}

Pathological changes observed in the epithelium of digestive lobules were classified in four degrees of pathology: none (0), mild (1), moderate (2), strong (3) and severe (4). The mean degree of pathological changes of the digestive lobules determined on 25 sections from each of the four snails per exposure, gave a mean degree of pathological changes (MDPC) per animal. The mean degree of pathological changes (MDPC) per exposure was determined based on the mean value from four animals.

\subsubsection{Percentage of lobules with intact epithelium (PLIE)}

The number of lobules in which MCs have no impact (corresponding to lobules classified as no pathological alteration) was determined for each exposure group in order to evaluate the percentage of lobules with intact epithelium (PLIE). From the PLIE of each of the four snails per exposure group, the mean percentage of lobules with intact epithelium (PLIE) per exposure was calculated.

\subsection{Immunohistochemistry}

In order to localize covalently bound MCs in snail tissues, four individuals, and five tissue sections per individual, from each exposure group were immunohistochemically stained for MCs and assessed after the exposure and depuration periods. Sections were fixed as described above. Immunohistochemical staining was carried out according to Ernst et al. (2007). Briefly, tissue sections on polylysine-coated glass slides were deparaffinized in $100 \%$ xylol, rehydrated in descending ethanol concentrations $(100,95$ and $70 \%$ ) and incubated with $1 \mathrm{mg} \mathrm{mL}^{-1}$ type XIV bacterial protease (Sigma-Aldrich, Germany) in PBS at 37 C for 10 min for antigendemasking. Endogenous biotin was blocked using a commercial avidin/biotin blocking kit (BioGenex, USA). Slides were further blocked with a casein solution (Power Block ${ }^{\mathrm{TM}}$, BioGenex, USA) for $10 \mathrm{~min}$ at room temperature. Rabbit anti MC-LR antibodies (\#2; kindly provided by Dr. John E. Eriksson, Åbo Akademi University, Turku, Finland) were diluted in Power Block ${ }^{\mathrm{TM}}$ (1:500) and applied to the tissue section in a humidified atmosphere for $16 \mathrm{~h}$ at $4{ }^{\circ} \mathrm{C}$. Antigen-antibody complexes were visualized using 
an IgAP-labelled, biotin-streptavidin amplified detection system (Super Sensitive ${ }^{T M}$, BioGenex, USA), levamisole block ( $5 \mathrm{mM}$ in MQ water) and Fast Red ${ }^{\mathrm{TM}}$ tablets (Roche, Germany). Sections were counter stained with Mayer's hematoxylin (Sigma-Aldrich, Germany) at room temperature for $6 \mathrm{~min}$, rinsed with tap water and preserved using Crystal/Mount ${ }^{\mathrm{TM}}$ (Biomeda, USA) and Shandon Histomount ${ }^{\mathrm{TM}}$ (Thermo Electron Corporation, Germany). Due to the multiple organic solvent and water washing steps, noncovalently bound MCs were removed. The immunohistochemical method therefore detects covalently bound MCs only.

Immunohistochemically stained slides were microscopically examined at 40-200-fold magnification. Digestive lobules, gonadic acini, kidney and foot sections were classified to be MC-positive when (i) MC-positive areas (recognized as a red colour against a blue stained background without unspecific red staining) were above background chromogen staining, and (ii) positive staining areas were consistently observable in two independently stained serial sections from the same tissue sample. Further quantitative and semi-quantitative parameters were created in order to evaluate the intensity of the MC-intoxication of the digestive and genital glands, as these organs showed the most prominent MC-positive staining. These parameters (see below) were evaluated based on 80 digestive lobules and 40 gonadic acini pictures, taken from five sections from each of the four snails per exposure using identical conditions (i.e., constant 62.5 -fold magnification and illumination for all acquisitions).

\subsubsection{Semi-quantification of the intensity of MC-immunopositive staining and percentage of $M C$-immunonegative digestive lobules and gonadic acini (\%NOMC)}

Immunopositive staining was ranked by visual assessing as none $(0)$, sporadic $(+)$, pronounced $(++)$ and extensive $(+++)$ in order to separate degrees of $M C$-positive staining and to have an overall idea of the contamination intensity. The percentage of digestive lobules or gonadic acini belonging to each degree was assessed via determining the number of lobules and acini classified in each degree divided by the total number of digestive lobules or gonadic acini in the tissue section. The percentage of digestive lobules or gonadic acini belonging to the degree 0 (MC-immunonegative lobules and acini) was particularly investigated and named the \%NoMC.

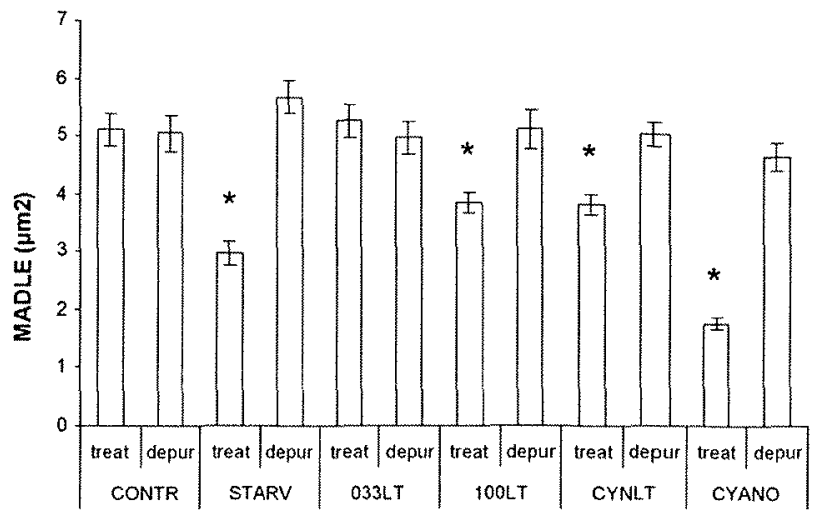

Fig. 2. Mean area of the digestive lobule epithelium (MADLE) in the digestive gland of $L$ stagnalis held in various treatment groups $(A=C O N T R ; B=S T A R V ; C=033 L T$ $\mathrm{D}=100 \mathrm{LT} ; \mathrm{E}=\mathrm{CYALT} ; \mathrm{F}=\mathrm{CYANO}$ ) after 5 weeks of treatment (treat) and 3 weeks of depuration (depur). The MADLE of control and treated snails were analysed for statistical differences using the Mann-Whitney $U$-test and indicated as ${ }^{*}$ for $p<0.05$. Values are given as mean \pm SE. See Table 1 for abbreviations of treatment groups.

\subsubsection{Quantification of the mean intensity of the MC-positive staining (MIMCS)}

The semi-quantitative classification of the MC-positive staining intensity within the digestive and genital glands performed by visual assessing and presented above (Section 2.4.1) was completed by a quantitative classification using the image $\mathrm{J}$ software [Wayne Rasband, National Institute of Mental Health, Maryland, USA]. RGB images were converted to CIELab by means of the "colour transformer" plugin [Maria E. Barilla, Electrical and Computer Engineering School, The University of Birmingham, UK]. Staining was analysed in the "a" component (colour transition from green to red). MC-positive staining intensity was determined as average pixel intensity over an area with a predefined size kept constant for all samples analysed. Individual measurements of each of the four snails per exposure group were combined to give the mean intensity of the MC staining (MIMCS) per exposure in the digestive lobules and gonadic acini.

Table 1

Distribution (in percent) of lobules from the digestive gland of $L$ stagnalis according to the degree of pathological changes after 5-week treatment and 3-week depuration in various treatment groups (CONTR = control snails fed on lettuce ad libitum; STARV $=$ starved snails; $033 \mathrm{LT}$ and $100 \mathrm{LT}=$ snails exposed to, respectively, 33 and $100 \mu \mathrm{g}$ MC-LR L ${ }^{-1}$ with lettuce ad libitum, CYANO and CYALT = snails exposed to MC-producing $\left(5 \mu \mathrm{g} \mathrm{L}^{-1}\right)$ Planktothrix agardhii respectively without and with lettuce ad libitum).

\begin{tabular}{|c|c|c|c|c|c|c|}
\hline \multirow[t]{2}{*}{ Medium food } & \multicolumn{6}{|c|}{ Treatment group } \\
\hline & CONTR dw let & STARV dw - & 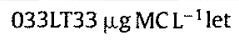 & $100 \mathrm{LT} 100 \mu g \mathrm{MCL}-1$ let & CYALTP. agardhiilet & CYANOP, agardhii- \\
\hline \multicolumn{7}{|l|}{ Treatment } \\
\hline 0 (PLIE) & $95.21 \pm 2.05$ & $75.04 \pm 1.38$ & $91.62 \pm 4.15$ & $55.34 \pm 3^{3.35^{*}}$ & $32.81 \pm 1.25^{*}$ & $4.41 \pm 0.82^{*}$ \\
\hline 1 & $2.90 \pm 1.98$ & $9.44 \pm 0.72$ & $5.09 \pm 1.05$ & $11.41 \pm 2.71$ & $14.13 \pm 2.29$ & $10.82 \pm 2.51$ \\
\hline 2 & $1.90 \pm 0.00$ & $9.40 \pm 0.85$ & $3.31 \pm 0.55$ & $11.44 \pm 3.81$ & $17.22 \pm 1.81$ & $23.54 \pm 1.89$ \\
\hline 3 & $0.00 \pm 0.00$ & $3.12 \pm 0.67$ & $0.00 \pm 0.00$ & $14.90 \pm 1.67$ & $20.34 \pm 3.92$ & $30.94 \pm 3.49$ \\
\hline 4 & $0.00 \pm 0.00$ & $3.04 \pm 0.05$ & $0.00 \pm 0.00$ & $7.02 \pm 1.39$ & $15.63 \pm 2.62$ & $30.42 \pm 2.98$ \\
\hline MDPC & $0.12 \pm 0.05$ & $0.48 \pm 0.15$ & $0.27 \pm 0.11$ & $0.88 \pm 0.13^{*}$ & $1.74 \pm 0.17^{*}$ & $2.73 \pm 0.16^{*}$ \\
\hline \multicolumn{7}{|l|}{ Depuration } \\
\hline O (PLIE) & $91.24 \pm 2.86$ & $90.27 \pm 2.92$ & $93.51 \pm 3.49$ & $87.40 \pm 3.21$ & $62.67 \pm 3.94^{*}$ & $50.01 \pm 3.69^{*}$ \\
\hline 1 & $7.42 \pm 0.48$ & $7.34 \pm 1.32$ & $4.35 \pm 1.83$ & $4.23 \pm 0.40$ & $12.20 \pm 1.83$ & $12.23 \pm 1.38$ \\
\hline 2 & $1.38 \pm 0.27$ & $0.00 \pm 0.00$ & $2.15 \pm 0.67$ & $3.24 \pm 1.05$ & $11.41 \pm 0.75$ & $12.52 \pm 2.09$ \\
\hline 3 & $0.00 \pm 0.00$ & $2.46 \pm 0.56$ & $0.00 \pm 0.00$ & $5.13 \pm 1.43$ & $8.93 \pm 1.76$ & $10.85 \pm 1.44$ \\
\hline 4 & $0.00 \pm 0.00$ & $0.00 \pm 0.00$ & $0.00 \pm 0.00$ & $0.00 \pm 0.00$ & $4.87 \pm 0.65$ & $14.50 \pm 2.11$ \\
\hline MDPC & $0.13 \pm 0.02$ & $0.15 \pm 0.08$ & $0.11 \pm 0.03$ & $0.17 \pm 0.05$ & $0.54 \pm 0.10^{*}$ & $1.38 \pm 0.28^{*}$ \\
\hline
\end{tabular}

$\mathrm{dw}=$ deionised water; let $=$ lettuce.

Pathological changes in lobules were classified as none ( 0 ), mild (1), moderate (2), strong ( 3 ) and severe (4). Four snails per treatment were assessed, by evaluating 25 sections per individual. For each treatment group, the percentage of lobules with intact epithelium (PLIE) is presented as mean $\pm S E$, and the mean degree of pathological changes (MDPC) is presented as median \pm MAD of the four individuals. The PLIE and the MDPC of control and treated snails was analysed for statistical differences using the Chi ${ }^{2}$ test and indicated as ${ }^{*}$ for $p<0.05$ 

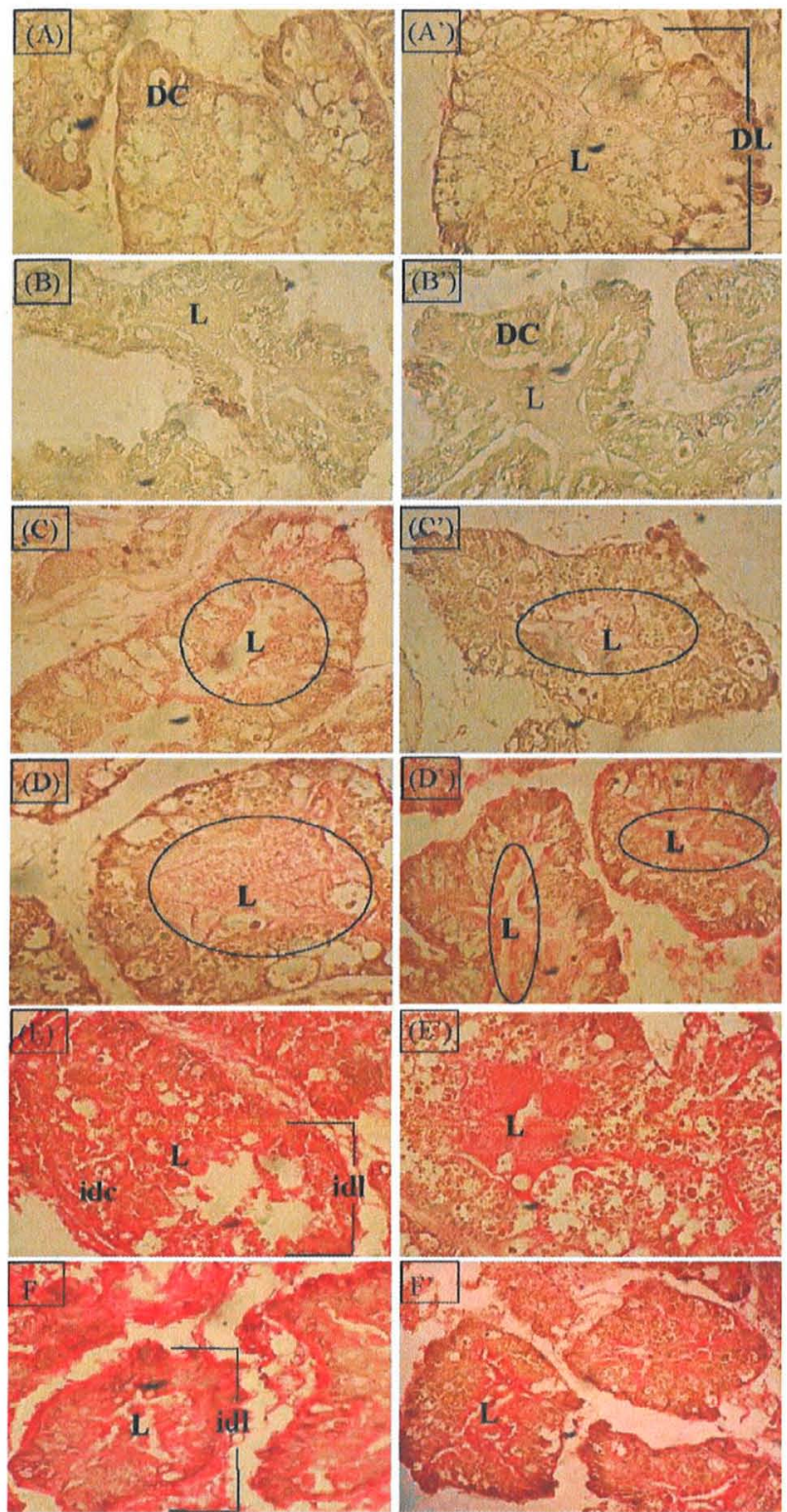

Fig. 3. Immunohistochemical determination of microcystin $(M C)$ in the digestive gland tissue of $L$. stagnalis held in various treatment groups ( $A=$ CONTR; $B=$ STARV; $C=033 \mathrm{LT}, \mathrm{D}=100 \mathrm{LT} ; \mathrm{E}=\mathrm{CYALT} ; \mathrm{F}=\mathrm{CYANO})$ after 5 weeks of treatment $(\mathrm{A}, \mathrm{B}, \mathrm{C}, \mathrm{D}$, $E$ and $F$ ) and 3 weeks of depuration ( $A^{\prime}, B, C^{\prime}, D^{\prime}, E^{\prime}$ and $F$ ). Sections were stained using $\mathrm{MC}$-antibodies and observed by light microscopy at 62.5-fold magnification. See Table 1 for abbreviations of treatment groups. MC accumulation dyed red (light colouration is additional highlighted by circles). Normal structure is given in capital letters: $\mathrm{DC}=$ digestive cells, $\mathrm{DL}=$ digestive lobule and $\mathrm{L}=$ lumen; damaged structure is labelled with small letters: idc $=$ impaired digestive cells and idl = impaired digestive lobules. (For interpretation of the references to colour in this figure legend, the reader is referred to the web version of the article.)

\subsection{Statistical analysis}

MDPC data are reported as median \pm median absolute deviation (MAD) of the individual ranks whereas other data are reported as mean \pm standard error (SE). Datasets were too small to allow verification of normal distribution (according to the Kolmogornov-Smirnov test) and were thus analysed employing non-parametric statistics, i.e., for differences between all the exposure groups the Kruskall-Wallis (KW) test for 2 by 2 exposure group comparisons:
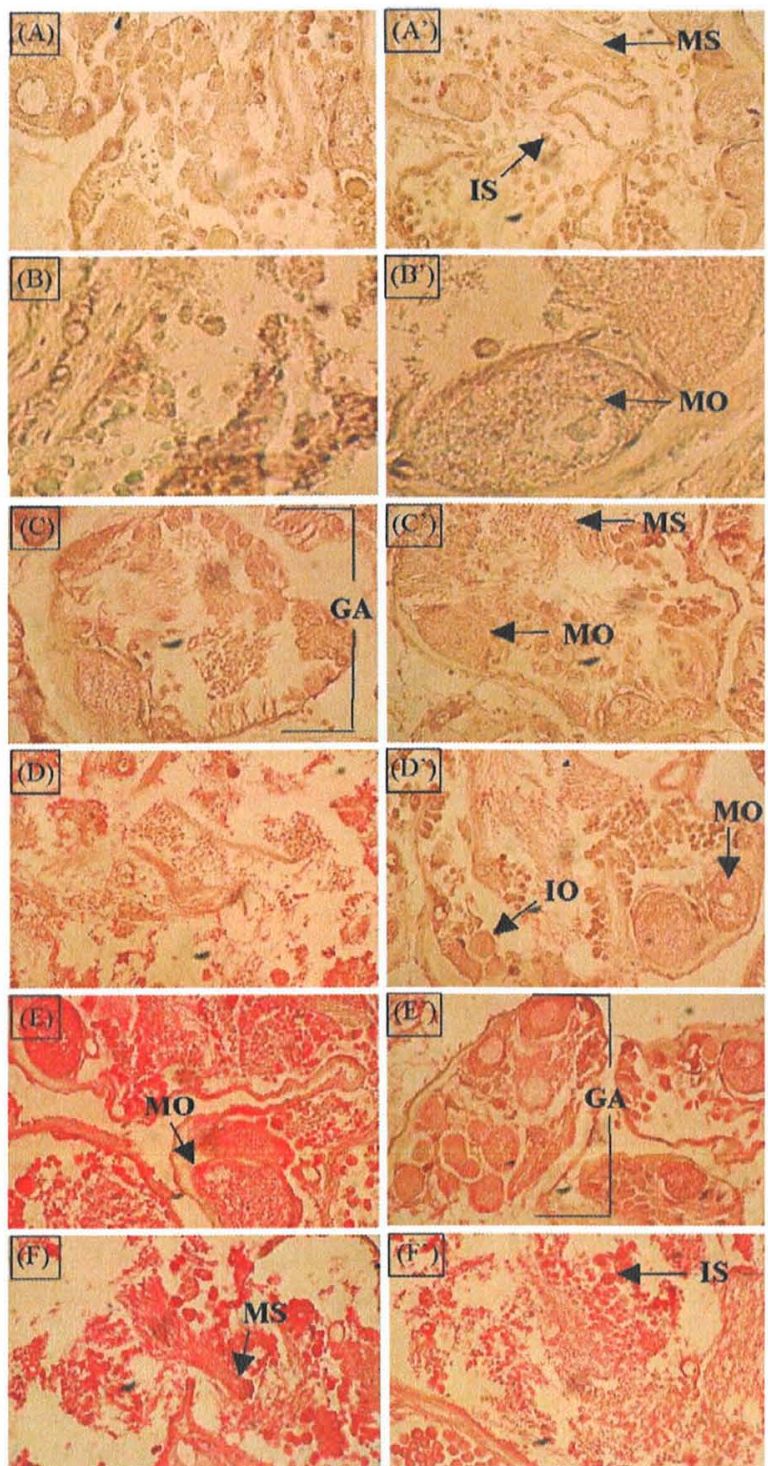

Fig. 4. Immunohistochemical determination of microcystin (MC) in the genital gland tissue of $L$. stagnalis held in various treatment groups $(A=C O N T R ; B=S T A R V$; $\mathrm{C}=033 \mathrm{LT}, \mathrm{D}=100 \mathrm{LT} ; \mathrm{E}=\mathrm{CYALT} ; \mathrm{F}=\mathrm{CYANO})$ after 5 weeks of treatment $(\mathrm{A}, \mathrm{B}, \mathrm{C}$, $D, E$, and $F$ ) and 3 weeks of depuration $\left(A^{\prime}, B^{\prime}, C^{\prime}, D^{\prime}, E^{\prime}\right.$ and $\left.F^{\prime}\right)$. Sections were stained using MC-antibodies and observed by light microscopy at 62.5 -fold magnification. See Table 1 for abbreviations of treatment groups. MC accumulation dyed red. Normal structure is given in capital letters: $G A=$ gonadic acini, $10=$ immature oocytes, $\mathrm{MO}=$ mature oocytes, $\mathrm{IS}=$ immature spermatozoids and $\mathrm{MS}=$ mature spermatozoids; no histopathological damage was detected in the genital gland. (For interpretation of the references to colour in this figure legend, the reader is referred to the web version of the article.)

(1) the Mann-Whitney $U$-test for the area of the digestive epithelium, the degree of pathological changes and the intensity of the MC-positive staining;

(2) the $\mathrm{Chi}^{2}$ test for the percentage of lobules with intact epithelium and the percentage of MC-immunonegative digestive lobules and gonadic acini (\%NoMC).

Significant differences were determined at $p<0.05$ (indicated as ${ }^{*}$ ). 
Table 2

Distribution (in percent) of lobules from the digestive and the genital glands of $L$ stagnalis according to the degree of MC-immunopositive staining after 5 -Week treatment and 3-week depuration in various groups (see Table 1 for abbreviations).

\begin{tabular}{|c|c|c|c|c|c|c|}
\hline \multirow[t]{2}{*}{ Medium food } & \multicolumn{6}{|c|}{ Treatment group } \\
\hline & CONTR dwlet & STARV dw - & $033 \mathrm{LT}_{3} 3 \mu \mathrm{g} \mathrm{MCL} \mathrm{L}^{-1}$ let & $100 \mathrm{LT} 100 \mu \mathrm{g} \mathrm{MCL}^{-1}$ let & CYALTP. agardhiilet & CYANOP. agardhii- \\
\hline \multicolumn{7}{|l|}{ Treatment } \\
\hline \multicolumn{7}{|l|}{ Digestive gland } \\
\hline 0 (\%NoMC) & $95.15 \pm 3.71$ & $94.74 \pm 2.91$ & $68.67 \pm 4.08$ & $25.02 \pm 3.39^{*}$ & $0.00 \pm 0.00^{*}$ & $0.00 \pm 0.00^{*}$ \\
\hline+ & $4.90 \pm 1.58$ & $5.30 \pm 0.95$ & $25.50 \pm 1.42$ & $37.52 \pm 4.15$ & $18.62 \pm 2.87$ & $4.73 \pm 0.86$ \\
\hline++ & $0.00 \div 0.00$ & $0.00 \pm 0.00$ & $5.90 \pm 1.47$ & $27.51 \pm 2.94$ & $40.63 \pm 3.64$ & $4.80 \pm 1.09$ \\
\hline+++ & $0.00 \pm 0.00$ & $0.00 \pm 0.00$ & $0.00 \pm 1.05$ & $10.00 \pm 1.07$ & $40.84 \pm 3.52$ & $90.52 \pm 3.99$ \\
\hline \multicolumn{7}{|l|}{ Genital gland } \\
\hline 0 (\%NoMC) & $97.92 \pm 3.21$ & $96.75 \pm 2.91$ & $95.00 \pm 4.83$ & $50.08 \pm 3.07^{*}$ & $23.83 \pm 2.46^{*}$ & $0.00 \pm 0.00^{*}$ \\
\hline+ & $2.10 \pm 0.76$ & $3.29 \pm 0.45$ & $5.00 \pm 1.12$ & $21.45 \pm 2.00$ & $26.73 \pm 3.75$ & $0.00 \pm 0.00$ \\
\hline++ & $0.00 \pm 0.00$ & $0.00 \pm 0.00$ & $0.00 \pm 0.00$ & $21.22 \pm 1.77$ & $21.54 \pm 1.99$ & $4.87 \pm 0.76$ \\
\hline$++t$ & $0.00 \pm 0.00$ & $0.00 \pm 0.00$ & $0.00 \pm 0.00$ & $7.40 \pm 0.85$ & $28.04 \pm 3.09$ & $95.11 \pm 4.39$ \\
\hline \multicolumn{7}{|l|}{ Depuration } \\
\hline \multicolumn{7}{|l|}{ Digestive gland } \\
\hline 0 (\%NoMC) & $97.21 \pm 4.25$ & $94.90 \pm 3.07$ & $89.62 \pm 3.05$ & $66.46 \pm 3.22$ & $40.00 \pm 2.55^{*}$ & $23.50 \pm 2.05^{*}$ \\
\hline+ & $2.80 \pm 0.18$ & $5.10 \pm 0.73$ & $5.23 \pm 1.27$ & $8.82 \pm 1.54$ & $40.64 \pm 3.87$ & $46.61 \pm 3.19$ \\
\hline++ & $0.00 \pm 0.00$ & $0.00 \pm 0.00$ & $5.18 \pm 1.94$ & $20.23 \pm 2.95$ & $13.31 \pm 1.76$ & $21.00 \pm 2.95$ \\
\hline+++ & $0.00 \pm 0.00$ & $0.00 \pm 0.00$ & $0.00 \pm 0.00$ & $4.60 \pm 1.35$ & $6.10 \pm 0.00$ & $8.88 \pm 1.39$ \\
\hline \multicolumn{7}{|l|}{ Genital gland } \\
\hline 0 (\%NOMC) & $97.23 \pm 4.25$ & $95.82 \pm 4.15$ & $95.32 \pm 3.33$ & $85.71 \pm 2.92$ & $54.52 \pm 2.05^{*}$ & $35.70 \pm 3.91^{*}$ \\
\hline+ & $2.80 \pm 0.18$ & $4.19 \div 0.51$ & $4.76+1.87$ & $14.30 \pm 0.99$ & $45.52 \pm 3.72$ & $64.30 \pm 3.54$ \\
\hline++ & $0.00 \pm 0.00$ & $0.00 \pm 0.00$ & $0.00 \pm 0.00$ & $0.00 \pm 0.00$ & $0.00 \pm 0.00$ & $0.00 \pm 0.00$ \\
\hline+++ & $0.00 \pm 0.00$ & $0.00 \pm 0.00$ & $0.00 \pm 0.00$ & $0.00 \pm 0.00$ & $0.00 \pm 0.00$ & $0.00 \pm 0.00$ \\
\hline
\end{tabular}

$\mathrm{dw}=$ deionised water; let $=$ lettuce

MC-immunopositive staining was classified as none $(0)$, sporadic ( + , pronounced $(++)$ and extensive $(+++)$ by visual assessing. Values are presented as mean \pm SE. Four snails per treatment were assessed, by evaluating five sections per individual. For each treatment group, the percentage of digestive Acini with no MC (\%NoMC) was assessed by averaging over the four individuals. The \%NoMC of control and treated snails was analysed for statistical differences using the Chi ${ }^{2}$ test and indicated as ${ }^{*}$ for $p<0.05$.

\section{Results}

\subsection{Histopathology}

3.1.1. Qualitative description of exposure-induced histopathology

Pathology in exposed snails was observed only in the digestive gland whereas no abnormality was observed in the kidney, foot and genital gland. In controls, the digestive gland consists of a series of lobules from a single layer of epithelial cells (Fig. $1 \mathrm{~A}$ and $A^{\prime}$ ). Epithelial cells in starved snails appeared flattened and the lumen of digestive lobules was enlarged compared to controls after the 5-week exposure period (Fig. 1B). Snails exposed to $33 \mu \mathrm{g} \mathrm{MC}$ $\mathrm{LRL}^{-1}$ showed slightly increased vacuolization of the digestive cells (Fig. 1C). Enhanced vacuolization, and single cell lysis and exfoliation into the lobular lumen were observed at $100 \mu{\mathrm{g} \mathrm{MC}-\mathrm{LRL}^{-1}}^{-1}$ (Fig. 1D). In contrast, severe necrosis in all digestive lobules, including alterations of the cell shape, separation of the basal lamina from the cell, widespread cell lysis with release of cytoplasmic content into the lobular lumen (Fig. 1E), was noted in snails exposed to MCproducing ( $5 \mu \mathrm{g} \mathrm{MC-LReq.} \mathrm{L}^{-1}$ ) P. agardhii with lettuce. The latter pathology was more pronounced in severity in snails exposed to $P$. agardhii without lettuce, culminating in almost complete loss of digestive gland tissue integrity (Fig. 1F).

Following the 3-week depuration period, the digestive gland of starved snails recovered (Fig. $1 \mathrm{~B}^{\prime}$ ). Similarly, most digestive lobules of snails previously exposed to MC-LR appeared normal albeit some lobules still contained vacuolated or exfoliated cells (Fig. $1 \mathrm{C}^{\prime}$ and $\mathrm{D}^{\prime}$ ). However, necrotic changes in snails previously exposed to toxic $P$. agardhii were still observable although they were less abundant than at the end of the exposure period (especially for snails that ingested lettuce with cyanobacteria) (Fig. $1 \mathrm{E}^{\prime}$ and $\mathrm{F}^{\prime}$ ).

\subsubsection{The mean areas of digestive lobule epithelium (MADLE)}

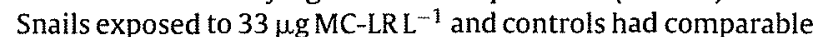
MADLE. In contrast, in all other exposure groups, snails showed significantly reduced MADLE (Fig. 2), compared to the corresponding controls, particularly those exposed to $P$. agardhii without lettuce. At the end of the depuration period, the areas of the digestive epithelium of exposure groups were comparable to those of the controls (Fig. 2).

Table 3

Intensity of MC-immunopositive staining in lobules from the digestive and genital glands of $L$ stagnalis according to the after 5 -week treatment and 3-week depuration in various groups (see Table 1 for abbreviations).

\begin{tabular}{|c|c|c|c|c|c|c|}
\hline \multirow[t]{2}{*}{ Medium food } & \multicolumn{6}{|c|}{ Treatment group } \\
\hline & CONTRdwlet & STARV dw - & $033 \mathrm{LT} 33 \mu \mathrm{g} \mathrm{MCL} \mathrm{ML}^{-1}$ let & $100 \mathrm{LT} 33 \mu \mathrm{g} \mathrm{MC} \mathrm{L-1}$ let & CYALTP. agardhiilet & CYANOP. agardhit \\
\hline \multicolumn{7}{|l|}{ Treatment } \\
\hline Digestive gland & $6.28 \pm 0.85$ & $8.02 \pm 0.71$ & $19.51 \pm 1.65$ & $38.02 \pm 2.56$ & $70.24 \pm 2.88$ & $91.60 \pm 4.70$ \\
\hline Genital gland & $5.64 \pm 1.01$ & $5.37 \pm 2.22$ & $13.94 \pm 2.14$ & $26.95 \pm 2.55$ & $49.23 \pm 3.69$ & $68.64 \pm 4.93$ \\
\hline \multicolumn{7}{|l|}{ Depuration } \\
\hline Digestive gland & $4.50 \pm 1.04$ & $6.44 \pm 1.67$ & $10.10 \pm 0.94$ & $17.33 \pm 1.08$ & $36.25 \pm 3.19$ & $63.52 \pm 3.65$ \\
\hline Genital gland & $3.69 \pm 0.33$ & $5.19 \pm 1.49$ & $7.44 \pm 0.49$ & $8.64 \pm 0.48$ & $15.91 \pm 1.67$ & $27.42 \pm 4.20$ \\
\hline
\end{tabular}

$\mathrm{d} w=$ deionised water; let $=$ lettuce.

Values assessed with the Image J software are presented as mean \pm SE. Four snails per treatment were assessed, by averaging five sections per individual. The mean intensity of MC-positive staining (MIMCS) was assessed by averaging over the four individuals per treatment. 
3.1.3. Percentage of Lobules with Intact epithelium (PLIE) and mean degree of pathological changes (MDPC)

The PLIE and MDPC of starved snails or those exposed to $33 \mu \mathrm{g}$ $M C-L R L^{-1}$ were comparable to those recorded in control snails. Concurrent with the pathology observed in the digestive lobules of snails exposed to the $100 \mu \mathrm{g} \mathrm{MC}-\mathrm{LRL}^{-1}$ and especially in snails exposed to toxic $P$. agardhii, a significant decrease of PLIE and an increase of MDPC were observed (Table 1). Accordingly, snails exposed to toxic $P$. agardhii without lettuce had the lowest PLIE and the highest MDCP. At the end of the depuration period, only snails previously fed on toxic $P$. agardhii showed a significantly decreased PLIE and an increased MDCP when compared to the corresponding controls (Table 1).

\subsection{MC-immunohistology}

\subsubsection{MC localization in L. stagnalis}

Control snails (CONTR and STARV) showed a negligible amount of background and thus false-positive MC-immunostaining (Fig. 3A and $B$ ), while snails exposed to either $P$. agardhii suspension (CYANO and CYALT) or dissolved MC-LR (033LT and 100LT) showed a strong (far above background) $\mathrm{MC}$-immunopositive staining (Figs. 3 and 4). At the end of the exposure period, MCimmunopositive staining was primarily observable in the lumen of digestive lobules and in digestive cells (Fig. 3), in the lumen of genital glands (i.e., oocytes, spermatozoids; Fig. 4), and in the digestive tract (i.e., prointestinal lumen), and was co-localized with the histopathological changes observed. In comparison, snails exposed to dissolved MC-LR had a lighter MC-immunopositive staining, primarily localized in the vacuoles of digestive cells (Fig. 3C), in the lumen of several isolated groups of digestive lobules (Fig. 3D), in spermatozoids (Fig. 4C) and oocytes (Fig. 4D) of few gonadic acini, whereas widespread and intense MC-immunopositivity was observed in snails exposed to toxic $P$. agardhii, including strong staining in the cytoplasm of digestive cells of all digestive lobules (Fig. 3E and F), and in spermatozoids and oocytes of gonadic acini of the whole genital gland (Fig. 4E and F). MCimmunopositivity was also observable in the same locations after the depuration period, however, with a much lower intensity (Figs. 3 and 4).

\subsubsection{Distribution of digestive lobules and gonadic acini} according to the degrees of MC-positive staining

The MC-positive staining was visually classified in 4 degrees, from degree 0 to degree 3. Snails exposed to high MC-LR concentrations (100LT) showed digestive and genital glands with significantly smaller percentage of digestive lobules and gonadic acini without MC-immunopositivity (\%NoMC, degree 0 ) than control and starved snails $(25.0 \pm 3.4 \%$ vs. $95.1 \pm 3.7 \%$ and $94.7 \pm 2.9 \%)$ (Table 2). When exposed to $P$. agardhii (either CYANO and CYALT) snails had zero $\mathrm{MC}$-immunonegative acini in the digestive gland, and only few in the genital gland (up to $23.8 \pm 2.5 \%$ with lettuce), thus presented the lowest \%NoMC. Accordingly, $90.5 \pm 3.9 \%$ of digestive lobules and $95.1 \pm 4.4 \%$ of gonadic acini were classified in the degree 3 of impairment for snails exposed to $P$. agardhii alone, whereas only respectively $10 \pm 1.0 \%$ and $7.4 \pm 0.8 \%$ for snails exposed to high MC-LR concentrations (100LT) and none for snails exposed to low MC-LR concentrations (33LT) (Table 2), corresponding with the observations on PLIE and MDCP. At the end of the depuration period, control snails and snails originally exposed to dissolved MC-LR had a similar \%NoMC in digestive and genital glands, whereas snails originally exposed to toxic $P$. agardhii showed a residual significantly lower \%NoMC (Table 2 ). Nevertheless, up to $46.6 \pm 3.2 \%$ of digestive lobules and $64.3 \pm 3.5 \%$ of gonadic acini of snails originally exposed to toxic $P$. agardhii were classified in the degree 1 of impairment, and only respectively up to
$8.9 \pm 1.4 \%$ and none in the $3 r d$ degree, suggesting a partial recovery (Table 2).

\subsubsection{Mean intensity of the MC-positive staining (MIMCS)}

The MIMCS was assessed by a software analysis. Snails exposed to either toxic $P$. agardhii or dissolved MC-LR showed significantly higher MIMCS in digestive and genital glands than controls after both exposure and depuration periods. Moreover, snails exposed to toxic $P$. agardhii presented significantly higher MIMCS in both glands than snails exposed to dissolved MC-LR (Table 3).

\section{Discussion}

Particles ingested by gastropods are ground in the gizzard and only particles $\leq 4 \mu \mathrm{m}$ pass toward the digestive gland, the others are compacted in the gizzard string fraction of faeces and directed toward the prointestine (Carriker, 1946). The digestive gland of gastropods consists of a series of lobules from a single layer of cells containing digestive cells, excretory cells, immature cells and stem cells (Carriker, 1946; Charrier, 1995). It is the primary site of secretion, intracellular (lysosomal) digestion, assimilation, accumulation, detoxification and metabolism (Charrier, 1995). Food material is engulfed via phagosomes by the digestive cells and digested in lysosomes. Nutrients are used directly within the cells or distributed systemically via the hemolymph system, whereas residues are excreted into the lobular lumen, then compacted in the digestive gland and excreted as faeces via the prointestine. Based on the observations in the present and previous studies (Lance et al., 2006; Zurawell et al., 2006), the digestion of whole filaments of $P$. agardhii containing MCs in $L$. stagnalis may occur according to the following routes:

(1) a disruption of cyanobacterial filaments occurs in the gizzard (Carriker, 1946) and a fraction of the released MCs is eliminated in the gizzard string fraction of the faeces (Zurawell et al., 2006);

(2) the other fraction of MCs is taken up by the digestive gland cells via phago-lysosomal uptake, or possibly if dissolved, via direct oatp (organic anion transporting peptide) family mediate transport.

Indeed, following 5-week exposure to MC-producing ( $5 \mu \mathrm{gL}^{-1}$ ) $P$. agardhii, the digestive gland of the gastropod $L$. stagnalis had severe histopathological changes (e.g., widespread cell lysis and necrosis) co-localized with a strong presence of covalently bound MCs. Similar pathological changes have already been described for L. stagnalis exposed to dissolved MC-LR (Zurawell et al., 2007) and fish fed with MC-producing cyanobacteria (Malbrouck and Kestemont, 2006; Ernst et al., 2007; Li et al., 2007). In mammalian and fish cells competent for MC uptake (e.g., hepatocytes and renal proximal cells), MCs form non-covalent and covalent interactions with the target enzymes PPs (PP1, 2A, 4, and 5). These interactions inhibit the catalytic subunits of the PPs thereby resulting in disorganization of cellular architecture and degeneration usually, followed by cell death (for reviews: Dietrich and Hoeger, 2005; Hastie et al., 2005; Malbrouck and Kestemont, 2006). In the study presented here, the co-localization of covalently bound MCs and digestive lobules presenting severe pathological changes (incl. cellular lysis and exfoliation) suggests MC-mediated PP inhibition in the digestive gland of $L$. stagnalis exposed to MC-producing $P$. agardhii. However, as MCS are known to covalently bind to PPs via the dehydroalanine moiety of MCs to the sulfhydril group of cysteine or methionine, $\mathrm{MC}$ covalent binding to peptides and proteins other than serine/threonine PPs cannot be excluded.

Over the 3-week depuration period, the necroses in the digestive gland of $L$. stagnalis exposed to toxic $P$. agardhii were partially 
reversible. At least some $\mathrm{MC}$ elimination appeared to have occurred as the MC-immunopositive staining was decreased at the end of the 3-week depuration period when compared to the intensity and area of MC-immunostaining observed at the end of the 5-week exposure period. A partial elimination of bound MCs (i.e., from 0 to $59 \%$ of bound MCs that were accumulated at the end of the exposure period according to treatments) was also observed in a recent study in which we determined the amount of bound and free MCs in $L$. stagnalis exposed to $P$. agardhii (producing 5 and $33 \mu \mathrm{g} \mathrm{MCs} \mathrm{L}^{-1}$ ) with or without lettuce (Lance et al., 2010). Elimination of covalently bound MCs may occur via detoxification pathways (e.g., via dissolution of the covalent bond and conjugation to glutathione (Pflugmacher et al., 1998)) and/or via degradation and consequent elimination of damaged cells. Several observations support the latter hypothesis since: (i) the covalent binding of MCs to PPs is known to be irreversible (for review: Dietrich and Hoeger, 2005), and (ii) the presence of regenerating lobules after depuration suggests the elimination of impaired cells [in the lumen of acini or by macrophages (Henry, 1987)] before the restoration of digestive epithelium from stem cells. The immature cells sequentially replace the digestive cells in normal conditions, whereas stem cells, highly protected, are capable of regenerating the epithelium in case of acute stress (Henry, 1987).

In contrast to the exposure to whole $P$-agardhii filaments, exposure of $L$. stagnalis to dissolved MC-LR ( 33 and $100 \mu \mathrm{g} \mathrm{L}^{-1}$ ) induced little to no adverse effects. The low degree of pathology observed coincided well with the weak signal of MC-immunopositive staining observed. These results are in accordance with a recent study in which we demonstrated an accumulation of bound and free MCS by $L$. stagnalis when exposed to $P$. agardhii (producing 5 and $33 \mu \mathrm{g} \mathrm{MCS} \mathrm{L}^{-1}$ ), whereas only limited accumulation of free MC-LR was noted when snails were exposed to dissolved MC-LR (33 or $100 \mu \mathrm{g} \mathrm{L}^{-1}$ ) (Lance et al., 2010). Moreover, the latter results are corroborated by earlier findings demonstrating that more severe adverse effects are noted in gastropods exposed to MCs by grazing on toxic cyanobacteria than by uptake of dissolved toxins, which may occur via oral water uptake or transintegumental penetration (Kotak et al., 1996; Zurawell et al., 1999; Kinnear et al., 2007; Lance et al., 2006, 2008).

When considering the rate of water ingestion of $L$. stagnalis (De With, 1996), the 5-week exposure period with $100 \mathrm{MC}-\mathrm{LR} \mu \mathrm{g} \mathrm{L}-1$ could result in an overall ingestion of approximately $2 \mu \mathrm{g}$ of MC-LR. A similar value is obtained during the 5-week exposure of $L$. stagnalis to $P$. agardhii producing $5 \mu \mathrm{g} \mathrm{MC-LReq} \mathrm{L}^{-1}$ (with $\mathrm{dmMC}-\mathrm{LR}$, dmMC-RR and MC-YR) (Lance et al., 2006). Thus theoretically both exposure pathways should lead to a similar "internal" exposure to MCs. However, the much lower degree of adverse effects observed during the exposure to dissolved MCs compared to cyanobacterial ingestion strongly suggests that less MCs were taken up during the dissolved MC exposure. The difference may be explained by:

(1) a difference in cumulative uptake amongst the two different exposure scenarios. Indeed, based on the physiological and anatomical features of $L$. stagnalis, grazed food is slowly ground, divided and passed through the digestive tract and excreted as fecal pellets. This process takes much longer than the rather rapid passing of dissolved matter through the digestive tract. Thus it is most likely that the food residual time is decisive for the uptake of MCs, i.e., the longer the residual time in the digestive tract the higher the quantity taken up by the digestive cells. The latter interpretation is corroborated by findings reported by Tencalla et al. (1994) who demonstrated that rainbow trout intra-peritoneally injected with MC-LR or orally gavaged with M. aeruginosa suspension containing MC-LR developed hepatic and renal pathology, whereas trout gavaged with dissolved MC-
LR or exposed to dissolved MC-LR in the ambient water did not present any pathological changes.

(2) a difference in toxicity of the various MC variants produced by $P$. agardhii. Indeed, the $P$. agardhii strain used in this study produced three MC variants (dmMC-LR, dmMC-RR and MC-YR) in various proportions. However, we previously observed that $L$. stagnalis accumulated a low amount of MCs when exposed to the same $P$. agardhii strain producing $33 \mu g$ MC-LReq $L^{-1}$ with $90.5 \%$ of dmMC-RR, whereas accumulated 8.2 times more free $\mathrm{MCs}$ (and 7.3 times more bound MCs) when the same cyanobacterial strain contained $33 \mu \mathrm{g} \mathrm{MC}$-LReq $\mathrm{L}^{-1}$ with $64.7 \%$ of MC-YR (Lance et al., 2010). In their review, Dietrich and Hoeger (2005) suggest that minor structural changes between MCs congeners may have major effects on uptake (e.g., different affinities to the oatps that allow MCs to penetrate across cell membranes), metabolization and excretion of MCs. Indeed, the assumed MC congener specific transport and ensuing toxicity was recently demonstrated by Fischer et al. (2010). Thus MC-YR might (i) more easily penetrates in digestive cells, and/or (ii) more easily links to Ppases, and/or (iii) fewer links with detoxification enzymes, than MC-LR and the other MCs congeners produced by $P$. agardhii (dmMC-LR and dmMC-RR). Moreover, the multiple compounds produced by cyanobacteria (identified toxins or not) might play a role in this difference of impact between crude extracts of cyanobacteria and purified toxins. Differences in mechanisms involved in toxicity in relation with MC variants and between ingestion of cyanobacterial cells vs. purified MCs require further studies.

\subsection{Consequences on L. stagnalis}

Our study is the first study comparing histopathological impacts of the two major intoxication routes for gastropods, already known to induce differences in MC accumulation, i.e., 1300 times more important in $L$. stagnalis after ingestion of toxic cyanobacteria than after dissolved MC-LR exposure (Gérard et al., 2005; Lance et al., 2006). Both exposure routes are also known to cause adverse effects on life-history traits (i.e., decreased fecundity and growth) of $L$. stagnalis (Gérard et al., 2005; Lance et al., 2007), due to the direct toxic effect of MCs on target cells (e.g., destruction) and/or the indirect energy trade-offs induced by higher energy demand for coping with toxic stress (e.g., cell restoration via activities of the stem cells, MCdetoxification processes). The stressful effect of MCs may thus alter the energy balance, as shown by juhel et al. (2006) for zebra mussels exposed to toxic $M$. aeruginosa. We found that snails exposed to MC-LR or to toxic cyanobacteria showed a diminution of the digestive epithelium area, as happened during starvation. Indeed, the digestive epithelium contains glycogen stores that can be mobilized by $L$. stagnalis during starvation (Livingstone and De Zwaan, 1983 ), inducing a reduction in its area, reversible when snails were fed on lettuce again.

Moreover, whatever intoxication route, MCs occurred in the genital gland including spermatozoids and oocytes (immature or mature). The genital gland is known to be the second major site of $\mathrm{MC}$ accumulation in gastropods after the digestive gland (Chen et al., 2005; Xie et al., 2007; Zhang et al., 2007). However, processes by which MCs pass from the digestive system to the genital gland are unknown but most likely involve hemolymph transport. It suggests that MCs are also excreted via the basal membrane of the digestive cells into the hemolymph and the hemocoel either as parent compound or metabolite and thus can be taken up by the reproductive organs. The spermatozoids and oocytes contaminated during gametogenesis in the genital gland are therefore likely to be either irreversibly damaged or viable but with dysfunctions. This could explain the decrease in the number of eggs laid or in the proportion of successfully developed surviving 15 -day old snails, both 
observed in $L$. stagnalis when parents have been exposed to toxic cyanobacteria or dissolved MC-LR (Gérard et al., 2005; Lance et al., 2007; Lance et al., in preparation).

In the field, freshwater gastropods may experience chronic ingestion of toxic cyanobacteria potentially producing different MC variants during the proliferation period, and acute exposure to extracellular MCs at the end of this period (Zurawell et al., 1999; Xie et al., 2007; Zhang et al., 2007). Consequently both intoxication routes potentially have a negative impact on gastropod communities, particularly in case of recurrent toxic cyanobacteria proliferations as demonstrated in the field by Gérard et al. (2008, 2009). Due to the key role of gastropods in structuring freshwater communities as herbivorous grazers and preys of numerous predators (Dillon, 2000; Kerans et al., 2005), this negative impact of toxic cyanobacteria on gastropods may have potential cascading effects on the equilibrium and functioning of ecosystems.

\subsection{Conclusion}

In conclusion, this study confirms the hypothesis of a negative impact of proliferations of toxic cyanobacteria on gastropod populations in the field due to adverse effects observed on the health and reproduction of snails during $\mathrm{MC}$ accumulation, mainly after ingestion of toxic cells and to a lesser extent by exposure to MCs dissolved in the medium. The effects of chronic exposure to toxic cyanobacteria that we observed at the individual level (survival, growth and reproduction) or sub-individual level (i.e., histological damages) remain to be investigated at the population level via both field (i.e., long-term studies in contaminated fresh waters) and modeling studies (i.e., impact on population dynamics depending on life-history strategies of the species).

Moreover, results presented in this study on the presence of covalently bound MCs in gastropod tissues illustrate the necessity to consider total and not only free MCs to properly assess the risk of toxin transfer to higher trophic levels. Concerning the covalent complex MC-PPs, its toxicity and bioavailability for the next trophic level still require to be elucidated.

\section{Conflict of interest}

The authors declare that there are no conflicts of interest.

\section{Acknowledgements}

This study was carried out with the financial support of the French Ministerial Grant to Emilie Lance and by the Deutscher Akademischer Austausch Dienst. Authors thank the Institut National de Recherche en Agronomie (U3E INRA, Rennes, France) for providing $L$ stagnalis individuals and the Museum National d'Histoire Naturelle (Paris, France) for providing P. agardhii strain.

\section{References}

Batista, T., de Sousa, G., Suput, J.S.. Rahmani, R., Suput, D., 2003. Microcystin-LR causes the collapse of actin filaments in primary human hepatocytes. Aquat. Toxicol. $65,85-91$

Carriker, M.R., 1946. Observations on the functioning of the alimentary system of the snail Lymnaea stagnalis appressa Say. Biol, Bull, 91, 88-111.

Charrier, M., 1995. Particularité du mêtabolisme digestif d'un gastéropode pulmoné phytophage, Helix aspersa Müller. Recherches histologiques, histochimiques, enzymologiques et microbiologiques. PhD thesis, University of Rennes, France.

Chen, J., Xie, P., Guo, L., Zheng, L., NI, L., 2005. Tissue distributions and seasonal dynamics of the hepatotoxic microcystins-LR and -RR in a freshwater snail ( $B e l$ lamya aeruginosa) from a large shallow, eutrophic lake of the subtropical China. Environ. Pollut. 134, 423-430.

De With, N.D., 1996. Oral water ingestion rate in the pulmonate freshwater snail, Lymnaea stagnalis. J. Comp. Physiol. B 166, 337-343.

Dietrich, D.R., Hoeger, S.j., 2005. Guidance values for microcystin in water and cyanobacterial supplement products (blue-green algae supplements): a reasonable or misguided approach? Toxicol. Appl. Pharmacol. 203, 273-289.
Dillon, R.T., 2000. Gastropods autecology. In: The Ecology of Freshwater Molluscs. Cambridge University Press, Cambridge, pp. 57-116.

Ernst, B., Dietz, L., Hoeger, S.J., Dietrich, D.R., 2005. Recovery of MC-LR in fish liver tissue. Environ. Toxicol. 20,449-458.

Ernst, B., Hoeger, S.j, O'Brien, E., Dietrich, D.R., 2007. Physiological stress and pathology in European whitefish (Coregonus lavaretus) induced by subchronic exposure to environmentally relevant densities of Planktothrix rubescens. Aquat. Toxicol. $79,31-40$.

Eriksson, J.E., Meriluoto, J.A.O., Lindholm, T., 1989. Accumulation of a peptide toxin from the cyanobacterium Oscillatoria agardhit in the freshwater mussel Anodonta cygnea. Hydrobiologia $183,211-216$.

Feurstein, D., Holst, K., Fischer, A., Dietrich, D.R., 2009. Oatp-associated uptake and toxicity of microcystins in primary murine whole brain cells. Toxicol. Appl. Pharmacol. $234(2), 247-255$.

Fischer, W.. Altheimer, S., Cattori, V., Meier, P.J., Dietrich, D.R., Hagenbuch, B., 2005. Organic anion transporting polypeptides expressed in liver and brain mediate uptake of microcystin. Toxicol. Appl. Pharmacol. 203 (3), 257-263.

Fischer, A., Hoeger, S.J., Stemmer, K., Feurstein, D.J., Knobeloch, D., Nussler, A., Dietrich, D.R., 2010. The role of organic anion transporting polypeptides (OATPS/SLCOs) in the toxicity of different microcystin congeners in vitro: a comparison of primary human hepatocytes and OATP-transfected HEK293 cells, Toxicol. Appl, Pharmacol, doi:10.1016/j.taap.2010.02.006, in press.

Gérard, C., Brient, L., Le Rouzic, B., 2005. Variation in the response of juvenile and adult gastropods (Lymnaea stagnalis) to cyanobacterial toxin (microcystin-LR). Environ, Toxicol. 20,592-596.

Gerard, C. Poullain, V., 2005. Vatiation in the response of the invasive species Potamopyrgus antipodarum (Smith) to natural (cyanobacterial toxin) and anthropogenic (herbicide atrazine) stressors. Environ. Pollut. 138, 28-33.

Gérard, C., Carpentier, A., Paillisson, J.M., 2008. Long-term dynamics and community structure of freshwater gastropods exposed to parasitism and other environmental stressors. Freshw. Biol. 53, 470-484.

Gérard, C., Poullain, V., Lance, E., Acou, A., Brient, L., Carpentier, A., 2009. Influence of toxic cyanobacteria on community structure and microcystin accumulation of freshwater molluscs. Environ. Pollut. 157, 609-617.

Hastie, C. J., Borthwick, E.B., Morrison, L.F., Codd, G.A., Cohen, P.T.W., 2005. Inhibition of several protein phosphatases by a non-covalently interacting microcystin and a novel cyanobacterial peptide, nostocyclin. Biochim. Biophys. Acta $(G) 1726$, 187-193.

Henry, M., 1987. La glande digestive de la palourde méditerranéenne Ruditapes decassatus $\mathrm{L}$, recherches ultrastructurales, cytochimiques, écophysiologiques et écotoxicolog!ques. PhD thesis. University of Aix-Marseille, France

Ibelings, B.W., Chorus, l., 2007. Accumulation of cyanobacterial toxins in freshwater "seafood" and its consequences for public health: a review. Environ. Pollut. 150, 177-192.

Juhel, G., Davenport, J., O'Halloran, J., Culloty, S.C., O'Riordan, R.M. James, K.F., Furey, A., Allis, 0 , 2006. Impacts of microcystins on the feeding behaviour and energy balance of zebra mussels, Dreissena polymorpha: a bioenergetics approach. Aquat. Toxicol. 79, 391 400.

Kerans, B.L,, Dybdahl, M.F., Gangloff, M.M., Jannot, J.E., 2005. Potamopyrgus antipodarum: distribution, density, and effects on native macroinvertebrate assemblages in the Greater Yellowstone Ecosystem. J. N. Am. Benthol. Soc. 24, 123-138.

Kinnear, S.H. Duivenvoorden, L.J., Fabbro, L.D., 2007. Sublethal responses in Melanoides tuberculata following exposure to Cylindrospermopsis raciborskii containing cylind rospermopsin. Harmful Algae 6, 642-650

Kotak, B.G., Zurawell, R.W., Prepas, E.E., Holmes, C.F.B., 1996. Microcystin-LR concentration in aquatic food web compartments from lakes of varying trophic status. Can. J. Fish. Aquat. Sci. 53, 1974-1985.

Lance, E. Brient, L. Bormans, M. Gérard, C. 2006. Interactions between cyanobacteria and Gastropods. I. Ingestion of toxic Planktothrix agardhii by Lymnaea stagnalis and the kinetics of microcystin bioaccumulation and detoxification. Aquat. Toxicol. 79, 140-148.

Lance, E., Paty, C., Bormans, M., Brient, L, Gérard, C., 2007. Interactions between cyanobacteria and Gastropods. II. Impact of toxic Planktothrix agardhit on the life-history traits of Lymnaea stagnalis. Aquat. Toxicol. 81, 389-396.

Lance, E., Bugajny, E., Bormans, M., Gérard, C., 2008. Consumption of toxic cyanobacteria by Potamopyrgus antipodarum (Gastropoda, Prosobranchia) and consequences on life traits and microcystin accumulation. Harmful Algae 7. 464-472.

Lance, E., Neffling, M.R., Gérard, C., Meriluoto, J., Bormans, M., 2010. Accumulation of free and covalently bound microcystins in tissues of Lymnaea stagnalis (Gastropoda) following toxic cyanobacteria or dissolved microcystin-LR exposure. Environ. Pollut. 158, 674-680.

Li, L., Xie, P., Chen, J., 2007. Biochemical and ultrastructural changes in the liver and kidney of the phytoplanktivorous silver carp feeding naturally on toxic Microcystis blooms in Taihu Lake, China, Toxicon 49, 1042-1053.

Livingstone, D.R., De Zwaan, A., 1983. Carbohydrate metabolism of gastropods. In: Wilbur, K.M.(Ed.), The Mollusca. Vol. 1: Metabolic Biochemistry and Molecular Mechanisms. Academic Press.

Malbrouck, C., Kestemont, P., 2006. Effects of microcystins on fish. Environ. Toxicol. Chem. 25, 72-86

Martins, J.C., Vasconcelos, V.M., 2009. Microcystin dynamics in aquatic organisms. J. Toxicol. Environ. Health, Part B 12,65-82.

Martoja, R., Martoja-Pierson, M., 1967. Inititation aux Echniques de L'histologie Animale. Masson, Issy-les-Moulineaux, France, $345 \mathrm{p}$. 
Maynes, J.T., Luu, H.A., Cherney, M.M., Andersen, R.J., Williams, D., Holmes, C.F.B., James, M.N.G., 2006. Crystal structures of protein phosphatase- 1 bound to motopurin and dihydromicrocystin-LA: elucidation of the mechanism of enzyme inhibition by cyanobacterial toxins. J. Mol. Biol. 356, 111-120.

Neffling, M.R., Lance, E., Meriluoto, J, 2010. Detection of free and covalently bound microcystins in animal tissues by liquid chromatography tandem mass spectrometry. Environ. Pollut. 158, 948-952.

Pflugmacher, S., Wiegand, C., Oberemm, A., Beattie, K.A., Krause, E., Codd, G.A., Steinberg, $C_{.}, 1998$, indentification of an enzymatically-formed glutathione conjugate of the cyanobacterial hepatotoxin microcystin-LR. The first step of detoxification. Biochem. Biophys. Acta 1425, 527 -533.

Tencalla, F., Dietrich, D., Schlatter, C., 1994. Toxicity of Microcystis aeruginosa peptide toxin to yearling rainbow trout (Oncorhynchus mykiss). Aquat. Toxicol. 30 , $215-224$

Wiegand, C., Pflugmacher, S., 2005. Ecotoxicological effects of selected cyanobacterial secondary metabolites a short review. Toxicol. Appl. Pharmacol. 203 , 201-218.

Xie, L., Yokoyama, A., Nakamura, K., Park, H., 2007. Accumulation of microcystins in various organs of the freshwater snail Sinotaia histrica and three fishes in a temperate lake, the eutrophic Lake Suwa, Japan. Toxicon 49, 646-652.
Yoshizawa, S., Matsushima, R, Watanabe, M.E., Harada, K.I., Ichihara, A., Carmichael, W.W., Fujiki. H., 1990. Inhibition of protein phosphatases by microcystis and nodularin associated with hepatotoxicity. J. Cancer Res. Clin. Oncol. 116, 609-614.

Zhang, D. Xie, P., Liu, Y., Chen, I. Liang, G., 2007. Bioaccumulation of the hepatotoxic microcystins in various organs of a freshwater snall from a subtropical Chinese lake, Taihu Lake, with dense toxic Microcystis blooms. Environ. Toxicol. Chem. $26,171-176$.

Zurawell, R.W., Kotak, B.G., Prepas, E.E., 1999. Influence of lake trophic status on the occurrence of microcystin-LR in the tissue of pulmonate snails. Freshw. Biol. 42. 707-718.

Zurawell, R.W., Chen, H., Burke,J.M., Prepas, E.E., 2005. Hepatotoxic cyanobacteria: a review of the biological importance of microcystins in freshwater environments. J. Toxicol. Environ. Health 8, 1-37.

Zurawell, R.W., Holmes, C.F.B., Prepas, E.E., 2006. Elimination of the cyanobacterial hepatotoxin microcystin from the freshwater pulmonate snail Lymnaea stagnalis jugularis (Say). J. Toxicol. Environ. Health 69, 303-318.

Zurawell, R.W., Goldberg, J.I. Holmes, C.F.B., Prepas, E.E., 2007. Tissue distribution and oral dose effects of microcystin in the freshwater pulmonate snail Lymnaea stagnalis jugularis (Say).J. Toxicol. Environ. Health 70, 620-626. 